\section{Pseudoexfoliation syndrome prevalence in Greek patients with cataract and its association to glaucoma and coronary artery disease}

GK Andrikopoulos', EK Mela', CD Georgakopoulos', GE Papadopoulos', AN Damelou', DK Alexopoulos ${ }^{2}$ and SP Gartaganis ${ }^{1}$
${ }^{1}$ Department of Ophthalmology, University of Patras Medical School, Patras, Greece

${ }^{2}$ Department of Internal Medicine, Division of Cardiology, University of Patras Medical School, Patras, Greece

Correspondence:

SP Gartaganis,

Department of

Ophthalmology, University of Patras Medical School,

Rion, Patras 26504, Greece

Tel: + 302610999286

Fax + 302610993994

E-mail s.gartag@

med.upatras.gr

Received: 8 March 2007 Accepted in revised form: 4 September 2007

Published online:

12 October 2007
Abstract

Purpose To investigate the prevalence of glaucoma and coronary artery disease (CAD) in patients with cataract and pseudoexfoliation (PEX) syndrome.

Methods Cross-sectional study of $\mathbf{2 1 4 0}$ consecutive patients with cataract admitted at the University Hospital of Patras, Greece, for cataract surgery. Only patients with senile cataract were included in this study. All patients underwent a complete ophthalmological examination that included slit-lamp evaluation with dilated pupil for PEX material in the anterior segment, intraocular pressure (IOP) measurements, and optic disc cup examination. They also underwent an evaluation for CAD by a cardiologist. CAD was considered present if a patient had a history of myocardial infarction, or ischaemia, or abnormal coronary angiography. The patients were classified into two groups: the PEX and the non-PEX group. Results One thousand and eighty-eight (50.8\%) patients were men and $1052(49.2 \%)$ were women. The overall prevalence of PEX syndrome was found to be $27.9 \%$ and it was found to increase with progressing age. Bilateral PEX was more frequent than unilateral PEX, with the percentage of bilateral PEX raising with progressing age. A total of 132 patients $(22.1 \%)$ in the PEX group exhibited glaucoma, while in the non-PEX group only $2.5 \%$ suffered glaucoma. PEX was also found to be positively associated with the risk for CAD among subjects 50 years or older.
No association between CAD and glaucoma was found.

Conclusions PEX syndrome constitutes a major glaucoma risk factor and a CAD risk factor. Patients with PEX should be informed and examined frequently as the risk is present throughout.

Eye (2009) 23, 442-447; doi:10.1038/sj.eye.6702992; published online 12 October 2007

Keywords: pseudoexfoliation syndrome; cataract; glaucoma; coronary artery disease; vascular disease; elastic microfibrillopathy

Introduction

Pseudoexfoliation (PEX) syndrome is an age-related disease characterized by the widespread deposition of an abnormal extracellular fibrillar material on many ocular and extraocular tissues.

The reported prevalence of PEX rates varies extensively from $0 \%$ to more than $40 \% .^{1-3}$ Ocular PEX has been associated to cataract and glaucoma development. The extraocular deposits have been localized to connectivetissue portions or septa traversing the organ tissue, associated with elastic fibres, collagen fibres, fibroblasts, and the walls of small blood vessels, ${ }^{4}$ suggesting the systemic nature of PEX. An overexpression of the basic fibroblast growth factor (bFGF), a disbalance of matrix metalloproteinases (MMPs)/tissue inhibitor of MMPs (TIMPs), and increased cellular and 
oxidative stress, describe a part of the pathological process that is characterized by an elastic microfibrillopathy. ${ }^{5-9}$

Although there is no clear-cut evidence that the deposits would cause degeneration of the extraocular tissues, they have been associated with transient ischaemic attacks ${ }_{,}^{10}$ Alzheimer's disease, ${ }^{11}$ asymptomatic myocardial dysfunction, ${ }^{12}$ sensorineural hearing loss, ${ }^{13}$ stroke, myocardial infarction, systemic hypertension, ${ }^{14}$ and aneurysm of the abdominal aorta. ${ }^{15}$

The purpose of this study was to investigate the prevalence of PEX syndrome in a Greek cataract population and its relation to glaucoma and coronary artery disease (CAD).

\section{Materials and methods}

The study was based on all patients admitted at the Department of Ophthalmology of the University Hospital of Patras, Greece, with the principal diagnosis being cataract to be operated during a 36-month period. The above hospital, together with another hospital, admits patients from South Western Greece, consisting of about 50\% urban and 50\% rural areas, with a population of 780000 inhabitants. Only patients with senile cataract were included in this study.

All patients underwent a comprehensive ophthalmological evaluation that included slit-lamp examination with dilated pupil. The patients were examined independently by two investigators, with the same instruments, in a dark examination room.

Following the examination, the patients were classified into two groups: the PEX group and the non-PEX group. They were considered to belong to the PEX group, when the typical greyish disc of deposits was observed on the central area of the anterior lens capsule, separated from a peripheral griddle of deposits by a clear zone, and/or when the typical flakes were found on the iris surface, in either eye. The consequent analyses were conducted on the basis of a person, not per eye. Subjects with aphakia or pseudophakia in the fellow eye were excluded because of difficulties in making a definitive diagnosis of the syndrome.

An average of three intraocular pressure (IOP) readings was computed for each eye using a Goldmann applanation tonometer, prior to pupillary dilation. The optic disc was examined by an indirect biomicroscopy using a $90 \mathrm{D}$ or a superfield retinal lens and the vertical cup/disc ratio of the optic disc was recorded.

Glaucoma suspect patients (IOP $>21 \mathrm{mmHg}$ or optic nerve abnormality suspicious for glaucoma) had a full threshold Humphrey 30-2 visual field. Patients were classified as definite glaucoma cases when they had at least two of the following: (a) mean IOP greater than
$21 \mathrm{mmHg}$, (b) cup/disc ratio $>0.6$ or cup/disc asymmetry between the two eyes $>0.2$, (c) visual field loss. Cases with rubeotic, angle closure, and secondary glaucoma (other from PEX) were excluded. In cases that we could not evaluate the field or optic disc due to a very developed cataract, we considered the eye to be glaucomatous when the IOP was higher than $24 \mathrm{mmHg}$. In patients under anti-glaucomatous treatment, we collected our information from their attending ophthalmologists.

All participants also underwent a cardiological evaluation for the presence of CAD by an independent experienced cardiologist. This was based on at least one of the following: (a) history of myocardial infarction diagnosed by symptoms plus either diagnostic electrocardiographic (ECG) changes or elevated cardiac enzyme levels, (b) history of ischaemia diagnosed either by the presence of angina and a positive exercise-stress ECG or by a thallium scan, (c) coronary angiography with obstructions $>50 \%$. Risk factors for CAD that were evaluated included the following: (a) age (10-year categories), (b) blood pressure $>140 / 90 \mathrm{mmHg}$ or history of hypertension: (yes/no), (c) blood cholesterol $>220 \mathrm{mg} / \mathrm{dl}$ or history of hypercholesterolemia: (yes/no), (d) blood glucose $>125 \mathrm{mg} / \mathrm{dl}$ or history of diabetes: (yes/no), (e) current cigarette smoking ( $\geqslant 1$ $\mathrm{cig} /$ day): (yes/no), (f) family history of premature CAD ( $<55$ years for male relatives and $<65$ for female relatives), among first-degree relatives: (yes/no), (g) obesity: body mass index (weight $/$ height $^{2}$ ) $\geqslant 30 \mathrm{~kg} / \mathrm{m}^{2}$ : (yes $/ \mathrm{no}$ ).

The experimental protocol adhered to the principles of the Declaration of Helsinki and was approved by the Ethics Committee of the University Hospital of Patras. Informed written consent was obtained from each patient.

\section{Statistical analysis}

The stratified analysis using the Mantel-Haenszel method was applied to test the difference in age-adjusted prevalence of PEX between men and women. The $\chi^{2}$-test was used to test: (a) the difference in PEX prevalence between the age groups, (b) the difference in glaucoma prevalence between the age groups (in the PEX and non-PEX group), and (c) the difference in age-adjusted prevalence of glaucoma between men and women (in the PEX and non-PEX group). The paired $t$-test was applied to test: (a) the difference in age- and sex-adjusted prevalence of glaucoma between PEX and non-PEX patients and (b) the difference in IOP between the affected and non-affected eye of patients with unilateral PEX. The statistical relationship of PEX syndrome to the prevalence of CAD was analysed using the weighted linear regression analysis. All statistical analyses were 
conducted using the STATA-8.2 statistical package. A $P$-value $<0.05$ was considered significant.

\section{Results}

We studied 2140 consecutive patients admitted at the Department of Ophthalmology of the University Hospital of Patras to be operated for senile cataract.

Age ranged from 57 to 91 years (mean, $\mathrm{SD}=71.4 \pm 7.5$ ). One thousand eighty-eight (50.8\%) patients were men and 1052 (49.2\%) were women. The overall prevalence of PEX syndrome was found to be $27.9 \%$. The distribution of PEX patients by sex and age is shown in Table 1 . No statistically significant difference was found between men and women (Mantel-Haenszel's test $=0.44$, $P=0.51$ ), but a statistically significant difference in the prevalence of the syndrome was observed between the age groups. The prevalence of PEX syndrome was found to increase with progressing age, from $1.2 \%$ in the 6th decade of life to about $34 \%$ in patients older than 80 years (Pearson's $x^{2}=45.6879, P<0.001$ ). This finding was consistent for both sexes (for men, Pearson's $x^{2}=23.9938$, $P<0.001$ and for women, Pearson $x^{2}=21.2554, P<0.001$ ).

Two hundred twenty-five (37.8\%) patients presented unilateral and $371(62.2 \%)$ bilateral PEX. With progressing age, the percentage of bilateral PEX was found to raise (from $52.0 \%$ in the 7th decade of life to $77.8 \%$ in patients older than 80 years).
The distribution of glaucoma patients by age, sex, and PEX is presented in Table 2. A total of 132 patients $(22.1 \%)$ in the PEX group exhibited glaucoma, in contrast with the non-PEX group where only $2.6 \%$ suffered glaucoma. In total, the PEX group was found to have an 8.5 -fold increased prevalence of glaucoma (statistically significant difference, $t=8.77, P<0.001)$. This prevalence was age dependent both in the PEX and the non-PEX group and the differences between the age groups were statistically significant (Pearson's $x^{2}=13.7456, P=0.003$ ). No statistically significant difference in prevalence of glaucoma (in the PEX and the non-PEX group) between the two sexes was found (Pearson's $x^{2}=2.7606$, $P=0.097$ ).

In the patients with unilateral PEX syndrome, the mean IOP in the affected eye was higher by a mean of $1.9 \mathrm{mmHg}$, as compared with the fellow eye $(17.6 \pm 2.6 \mathrm{vs}$ $15.7 \pm 2.3 \mathrm{mmHg}$ ). The difference between the affected and non-affected eye was statistically significant $(t=12.7$, $P<0.001)$. The mean IOP in bilateral PEX patients was $18.1 \pm 2.2 \mathrm{mmHg}$ and in non-PEX patients $14.9 \pm 2.1 \mathrm{mmHg}$.

The prevalence of CAD between the PEX and the non-PEX group is shown in Table 3. One hundred fourteen $(19.1 \%)$ patients with PEX deposits were found to have CAD, while in the non-PEX group the prevalence of CAD was $11.5 \%$. In addition, the prevalence of PEX among cataract patients with CAD was higher (39.0\%)

Table 1 Distribution of the PEX and the non-PEX patients by age and sex

\begin{tabular}{|c|c|c|c|c|c|c|}
\hline \multirow[t]{2}{*}{ Age group (years) } & \multicolumn{2}{|c|}{ Men } & \multicolumn{2}{|c|}{ Women } & \multicolumn{2}{|c|}{ Total } \\
\hline & $\begin{array}{l}\text { PEX group } \\
\text { no. }(\%)\end{array}$ & $\begin{array}{c}\text { Non-PEX group } \\
\text { no. }(\%)\end{array}$ & $\begin{array}{l}\text { PEX group } \\
\text { no. }(\%)\end{array}$ & $\begin{array}{c}\text { Non-PEX group } \\
\text { no. }(\%)\end{array}$ & $\begin{array}{l}\text { PEX group } \\
\text { no. }(\%)\end{array}$ & $\begin{array}{c}\text { Non-PEX group } \\
\text { no. }(\%)\end{array}$ \\
\hline $50-59$ & $1(2.2)$ & $45(97.8)$ & $0(0)$ & $36(100)$ & $1(1.2)$ & $81(98.8)$ \\
\hline $60-69$ & $68(22.1)$ & $240(77.9)$ & $55(24.3)$ & $171(75.7)$ & $123(23.0)$ & $411(77.0)$ \\
\hline $70-79$ & $151(29.1)$ & 368 (70.9) & $168(30.2)$ & $389(69.8)$ & $319(29.6)$ & $757(70.4)$ \\
\hline$\geqslant 80$ & $72(33.5)$ & $143(66.5)$ & $81(34.8)$ & $152(65.2)$ & $153(34.2)$ & $295(65.8)$ \\
\hline Total & $292(26.8)$ & $796(73.2)$ & $304(28.9)$ & $748(71.1)$ & $596(27.9)$ & $1544(72.1)$ \\
\hline
\end{tabular}

PEX, pseudoexfoliation.

Table 2 Glaucoma prevalence among the PEX and the non-PEX group, by age and sex

\begin{tabular}{|c|c|c|c|c|c|c|}
\hline \multirow[t]{2}{*}{ Age group (years) } & \multicolumn{2}{|c|}{ Men with glaucoma } & \multicolumn{2}{|c|}{ Women with glaucoma } & \multicolumn{2}{|c|}{ Total with glaucoma } \\
\hline & $\begin{array}{l}\text { PEX group } \\
\text { no. }(\%)\end{array}$ & $\begin{array}{c}\text { Non-PEX group } \\
\text { no. }(\%)\end{array}$ & $\begin{array}{l}\text { PEX group } \\
\text { no. }(\%)\end{array}$ & $\begin{array}{c}\text { Non-PEX group } \\
\text { no. }(\%)\end{array}$ & $\begin{array}{l}\text { PEX group } \\
\text { no. }(\%)\end{array}$ & $\begin{array}{c}\text { Non-PEX group } \\
\text { no. }(\%)\end{array}$ \\
\hline $50-59$ & 0/1 (0) & $1(2.2)$ & - & $0(0)$ & 0/1 (0) & $1(1.2)$ \\
\hline $60-69$ & $10(14.7)$ & $6(2.5)$ & $10(18.2)$ & $4(2.3)$ & $20(16.3)$ & $10(2.4)$ \\
\hline $70-79$ & $29(19.2)$ & $11(3.0)$ & 45 (26.8) & $9(2.3)$ & $74(23.2)$ & $20(2.6)$ \\
\hline$\geqslant 80$ & $15(20.8)$ & $5(3.5)$ & $23(28.4)$ & $4(2.6)$ & $38(24.8)$ & $9(3.1)$ \\
\hline Total & $54(18.5)$ & $23(2.9)$ & $78(25.7)$ & $17(2.3)$ & $132(22.1)$ & $40(2.6)$ \\
\hline
\end{tabular}

PEX, pseudoexfoliation. 
Table 3 Coronary artery disease prevalence between the PEX and the non-PEX group, by age and sex

\begin{tabular}{|c|c|c|c|c|c|c|}
\hline \multirow[t]{2}{*}{ Age group (years) } & \multicolumn{2}{|c|}{ Men with $C A D$} & \multicolumn{2}{|c|}{ Women with $C A D$} & \multicolumn{2}{|c|}{ Total with $C A D$} \\
\hline & $\begin{array}{c}\text { PEX group } \\
\text { no. }(\%)\end{array}$ & $\begin{array}{c}\text { Non-PEX group } \\
\text { no. }(\%)\end{array}$ & $\begin{array}{c}\text { PEX group } \\
\text { no. }(\%)\end{array}$ & $\begin{array}{c}\text { Non-PEX group } \\
\text { no. }(\%)\end{array}$ & $\begin{array}{c}\text { PEX group } \\
\text { no. }(\%)\end{array}$ & $\begin{array}{c}\text { Non-PEX group } \\
\text { no. }(\%)\end{array}$ \\
\hline $50-59$ & 0/1 (0) & $3(6.7)$ & - & $1(2.8)$ & 0/1 (0) & $4(4.9)$ \\
\hline $60-69$ & $12(17.6)$ & $26(10.8)$ & $5(9.1)$ & $12(7.0)$ & $17(13.8)$ & $38(9.2)$ \\
\hline $70-79$ & $33(21.9)$ & $57(15.5)$ & $26(15.5)$ & $36(9.3)$ & $59(18.5)$ & $93(12.3)$ \\
\hline$\geqslant 80$ & $20(27.8)$ & $25(17.5)$ & $18(22.2)$ & $18(11.8)$ & $38(24.8)$ & $43(14.6)$ \\
\hline Total & 65 (22.3) & 111 (13.9) & 49 (16.1) & $67(9.0)$ & 114 (19.1) & 178 (11.5) \\
\hline
\end{tabular}

CAD, coronary artery disease; PEX, pseudoexfoliation.

than its prevalence in cataract participants without CAD $(26.1 \%)$. After adjustment by logistic regression for age, serum cholesterol, blood pressure, current smoking, diabetes, family history of premature CAD, and obesity, PEX syndrome was found to be positively associated with the risk for CAD among subjects 50 years or older (odds ratio $=2.12$, with 95\% confidence interval 1.51-2.97)

No association between CAD and glaucoma was found as the prevalence of CAD among the glaucoma patients was $13.4 \%$ (23 of 172), while its prevalence among the non-glaucoma patients was $13.7 \%$ (269 of 1968), which remains constant after adjustment for risk factors known to be associated with CAD.

In addition to increasing age, no other risk factor for CAD was found to be significantly associated with PEX on multivariate analysis.

\section{Discussion}

The reported frequency of PEX syndrome varies extensively, even from place to place in the same country, depending on the examiner or other factors. Some of these factors include the patients' selection, the ethnic composition of the population, the clinical criteria for diagnosis, and the thoroughness of examination. Genetic, environmental (sunlight) or other influences may be involved in the aetiology and pathogenesis of the syndrome. Studies from different regions in Greece show that the PEX frequency differentiates. Specifically, in the island of Crete, in a randomized sample, PEX was found to occur in $16.1 \%$ of patients over 40 years; ${ }^{16}$ in Epirus, in patients that examined in an ophthalmological general centre, the frequency of PEX was found to be $24.3 \%$ in patients over 50 years; ${ }^{17}$ and in Thessaloniki, it has been reported to be $28 \%$ in cataract patients. ${ }^{18}$ High rates have also been reported in the older age groups ( $>70$ years) in northern Finland (25.3\%), Iceland (31.5\%), Saudi Arabia (26.5\%), and among Lapps (35.3\%). ${ }^{19}$ The PEX syndrome prevalence observed in our study $(27.9 \%)$ seems to be in consistence with the prevalence reported from other Mediterranean and Scandinavian countries, but it is significantly higher than the one reported in Central European cataract cohorts. The reason for this is still unclear. Significant comparisons are those made in different populations by the same investigator and by the same technique. So, Forsius ${ }^{2}$ looking at persons over 60 years of age in different countries, including Lapps, Finns, Eskimos, Icelanders, Peruvian, Indians, Russians, and Tunisians, found prevalence ranging from $0 \%$ in Greenland Eskimos to $21 \%$ in Finns, Lapps, Icelanders, and Russians in Novosibirsk.

In this study there was a selection bias. We studied PEX syndrome prevalence in a cataract population. So, the observations may not reflect the real distribution of PEX in the general population of the area. Other sources have suggested higher prevalence of PEX in cataract patients. ${ }^{3,20}$ As the study was not randomized, comparisons among analogous study groups are also interesting. Hietanen $e t a l^{21}$ found the frequency of PEX syndrome $25.2 \%$ in patients scheduled for cataract surgery, in Finland and Teshome and Regassa, ${ }^{22} 39.3 \%$, in Ethiopia. $^{2}$ In a review, Forsius ${ }^{3}$ reported the frequency of PEX in patients with cataract vary from $0.3 \%$ in Poland, $3.5 \%$ in France, $18 \%$ in Norway to $33 \%$ in Finland. Thus, our study may demonstrate the commonly known late manifestation of the syndrome and not the preclinical early stages.

We also found that both sexes are equally affected by PEX. Reviewing the literature, we observed that there are conflicting results concerning PEX prevalence between the two sexes. Some studies report that PEX is more frequent among women, ${ }^{14,23}$ but this preponderance of women has not been confirmed in other populations. ${ }^{16,18}$

In consistence with all previous reports, we observed that PEX frequency increases with the progressing of age, as the syndrome is considered an age-related disease.

In total, bilateral PEX syndrome in our study was almost 1.6 times more common than unilateral PEX, with bilateral PEX increasing with age from $52.0 \%$ in the 7 th decade to $77.8 \%$ in patients older than 80 years. Actually, the syndrome is rather bilateral with asymmetric presentation, as PEX fibres have been observed on 
electron microscopy in the conjunctiva ${ }^{24}$ and orbital tissues ${ }^{25}$ of the clinically uninvolved fellow eyes. Also immunohistochemical and ultrastructural findings, typical of PEX fibres, have been revealed in the iris of all unaffected fellow eyes. ${ }^{26}$

The association of PEX syndrome to glaucoma is well established. . $1,17,27,28$ In our study, the PEX-population had a mean age-dependent 8.5 -fold increased prevalence of glaucoma. Ringvold et $a l^{28}$ found glaucoma in 30\% of patients with PEX syndrome detected on screening, as opposed to $4 \%$ of those without PEX, while Kozobolis et $a l^{16}$ found IOP $>21 \mathrm{mmHg}$ in $28.8 \%$ of PEX patients and in $5.4 \%$ of non-PEX patients.

Of the 371 patients having bilateral PEX, 93 (25.1\%) had glaucoma, $50(53.8 \%)$ of them bilaterally. Among the 225 participants with unilateral PEX, 39 (17.3\%) had glaucoma, $9(23.1 \%)$ of them bilaterally and only 2 had glaucoma in the non-PEX fellow eye. These results suggest a possible correlation between the amount of 'dandruff-like' material and its effect in causing glaucoma in some individuals. In pseudoexfoliative eyes, the tendency of developing glaucoma is cumulative over time. In a prospective 10-year follow-up study, Puska ${ }^{29}$ found conversion into exfoliation glaucoma $32 \%$ in the initially exfoliative eyes and primary open-angle glaucoma in $3.5 \%$ of non-PEX eyes.

In this study, the prevalence of CAD in cataract patients with PEX syndrome was higher (19.1\%) than the prevalence in cataract participants without PEX (11.5\%).

The association of PEX material and elastosis of blood vessel wall has been shown in several studies. ${ }^{4,15,24,25}$ But the association of PEX syndrome to vascular disease remains controversial. A possible link between PEX syndrome and cardiovascular or cerebrovascular disease has been supported by many sources. ${ }^{10,12,14,30-35} \mathrm{In}$ addition, elevated plasma homocysteine, a risk factor for cardiovascular disease, has been found more common in PEX syndrome than in healthy controls. ${ }^{36}$ Considering the reports above, one should suggest that slit-lamp examination of the eye could identify an important marker for the risk of a systemic vascular disease.

Yet, in other studies no association between ocular PEX and cardiovascular or cerebrovascular disease has been found. . $^{37-40}$

In summary, PEX syndrome is considered a systemic process with abnormal matrix synthesis, particularly as related to elastic tissue components. The pathogenesis of PEX-glaucoma and CAD in PEX patients may reflect different positions of the same process: the elastosis of the lamina cribrosa ${ }_{1}^{41}$ the trabecular meshwork, ${ }^{42}$ the wall of the posterior cilliary arteries ${ }^{25}$ in glaucoma, and the elastosis of cardiovascular tissues ${ }^{4,43}$ in CAD.

The results of this study also demonstrate that PEX syndrome is associated with glaucoma and CAD.
It is a study of people at one point of time to determine whether PEX syndrome is associated with the occurrence of glaucoma and CAD (cross-sectional study). Because the disease (glaucoma, CAD) outcome and the possible risk factor (PEX syndrome) are measured at the same time, the study provides a 'snapshot' view of their relationship. PEX and glaucoma-CAD have already occurred and we cannot be sure which happened first. So the study cannot provide an accurate information about causality.

Many major questions about PEX syndrome still remain obscure. The variation of its prevalence in different populations, its pathogenesis, and the composition of extraocular deposits are some of the topics that have to be clarified.

Nevertheless, PEX constitutes a major glaucoma risk factor and possibly a CAD risk factor; patients with PEX syndrome should be informed and examined frequently as the risk may be present throughout.

\section{References}

1 Ringvold A. Epidemiology of the pseudo-exfoliation syndrome. Acta Ophthalmol Scand 1999; 77: 371-375.

2 Forsius H. Prevalence of pseudoexfoliation of the lens in Finns, Lapps, Icelanders, Eskimos and Russians. Trans Ophthalmol Soc UK 1979; 99: 296-298.

3 Forsius H. Exfoliation syndrome in various ethnic populations. Acta Ophthalmol Suppl 1988; 184: 71-85.

4 Schlotzer-Schrehardt UM, Koca MR, Naumann GO, Volkholz H. Pseudoexfoliation syndrome. Ocular manifestation of a systemic disorder? Arch Ophthalmol 1992; 110: $1752-1756$.

5 Gartaganis SP, Georgakopoulos CD, Exarchou AM, Mela EK, Lamari F, Karamanos NK. Increased aqueous humor basic fibroblast growth factor and hyaluronan levels in relation to the exfoliation syndrome and exfoliative glaucoma. Acta Ophthalmol Scand 2001; 79: 572-575.

6 Gartaganis SP, Georgakopoulos CD, Mela EK, Exarchou A, Ziouti N, Assouti $\mathrm{M}$ et al. Matrix metalloproteinases and their inhibitors in exfoliation syndrome. Ophthalmic Res 2002; 34: 165-171.

7 Zenkel M, Kruse FE, Junemann AG, Naumann GOH, Schlotzer-Schrehardt U. Clusterin deficiency in eyes with pseudoexfoliation syndrome may be implicated in the aggregation and deposition of pseudoexfoliative material. Invest Ophthalmol Vis Sci 2006; 47: 1982-1990.

8 Ritch R, Schlotzer-Schrehardt U. Exfoliation syndrome. Survey Ophthalmol 2001; 45: 265-315.

9 Schlotzer-Schrehardt UM, Naumann GO. Ocular and systemic pseudoexfoliation syndrome. Am J Ophthalmol 2006; 141: 921-937.

10 Repo LP, Terasvirta ME, Koivisto KJ. Generalized transluminance of the iris and the frequency of the pseudoexfoliation syndrome in the eyes of transient ischemic attack patients. Ophthalmology 1993; 100: 352-355.

11 Linner E, Popovic V, Gottfries CG, Jonsson M, Sjogren M, Wallin A. The exfoliation syndrome in cognitive impairment 
of cerebrovascular or Alzheimer's type. Acta Ophthalmol Scand 2001; 79: 283-285.

12 Bojic L, Ermacora R, Polic S, Ivanisevic M, Mandic Z, Rogosic $\mathrm{V}$ et al. Pseudoexfoliation syndrome and asymptomatic myocardial dysfunction. Graefes Arch Clin Exp Ophthalmol 2005; 243: 446-449.

13 Cahill M, Early A, Stack S, Blayney A, Eustace P. Pseudoexfoliation and sensorineural hearing loss. Eye 2002; 16: 261-266.

14 Mitchell P, Wang JJ, Smith W. Association of pseudoexfoliation syndrome with increased vascular risk. Am J Ophthalmol 1997; 124: 685-687.

15 Schumacher S, Schlotzer-Schrehardt U, Martus P, Lang W, Naumann GOH. Pseudoexfoliation syndrome and aneurysms of the abdominal aorta. The Lancet 2001; 357: 359-360.

16 Kozobolis VP, Papatzanaki M, Vlachonikolis IG, Tsambarlakis IG. Epidemiology of pseudoexfoliation in the island of Crete (Greece). Acta Ophthalmol Scand 1997; 75: 726-729.

17 Stefaniotou M, Petroutsos G, Psilas K. The frequency of pseudoexfoliation in a region of Greece (Epirus). Acta Ophthalmol (Copenh) 1990; 68: 307-309.

18 Konstas A, Dimitrakoulias N, Kourtzidou O, Filidis K, Bufidis K, Benos A. Frequency of exfoliation syndrome in Greek cataract patients. Acta Ophthalmol Scand 1996; 74: 478-482.

19 Vesti E, Kivela T. Exfoliation syndrome and exfoliation glaucoma. Prog Retin Eye Res 2000; 19: 345-368.

20 Roth M, Epstein DL. Exfoliation syndrome. Am J Ophthalmol 1980; 89: 477-481.

21 Hietanen J, Kivela T, Vesti E, Tarkkanen A. Exfoliation syndrome in patients scheduled for cataract surgery. Acta Ophthalmol (Copenh) 1992; 70: 440-446.

22 Teshome T, Regassa K. Prevalence of pseudoexfoliation syndrome in Ethiopian patients scheduled for cataract surgery. Acta Ophthalmol Scand 2004; 82: 254-258.

23 Hiller R, Sperduto RD, Krueger DE. Pseudoexfoliation, intraocular pressure and senile lens changes in a population-based survey. Arch Ophthalmol 1982; 100: 1080-1082.

24 Streeten BW, Bookman L, Ritch R, Prince AM, Dark AJ. Pseudoexfoliative fibrillopathy in the conjunctiva. A relation to elastic fibers and elastosis. Ophthalmology 1987; 94: 1439-1449.

25 Schlotzer-Schrehardt UM, Kuchle M, Naumann GOH. Electron-microscopic identification of pseudoexfoliation material in extrabulbar tissue. Arch Ophthalmol 1991; 109: 565-570.

26 Hammer T, Schlotzer-Schrehardt UM, Naumann GOH. Unilateral or asymmetric pseudoexfoliation syndrome? An ultrastructural study. Klin Monatsbl Augenheilkd 2000; 217: 100-108.

27 Kozart D, Yanoff M. Intraocular pressure status in 100 consecutive patients with exfoliation syndrome. Ophthalmology 1982; 89: 214-218.
28 Ringvold A, Blika S, Elsas T, Guldahl J, Brevik T, Hesstvedt $\mathrm{P}$ et al. The middle-Norway eye-screening study.II. Prevalence of simple and capsular glaucoma. Acta Ophthalmol (Copenh) 1991; 69: 273-280.

29 Puska PM. Unilateral exfoliation syndrome: conversion to bilateral exfoliation and to glaucoma: a prospective 10-year follow-up study. J Glaucoma 2002; 11: 517-524.

30 Atalar PT, Atalar E, Kilic H, Abbasoglu OE, Ozer N, Aksoyek $\mathrm{S}$ et al. Impaired systemic endothelial function in patients with pseudoexfoliation syndrome. Int Heart J 2006; 47: 77-84

31 Citirik M, Acaroglu G, Batman C, Yildiran L, Zilelioglu O. A possible link between the pseudoexfoliation syndrome and coronary artery disease. Eye 2007; 21: 11-15.

32 Damji KF, Bains HS, Amjadi K, Dohadwala AA, Valberg JD, Chevrier R et al. Familiar occurrence of pseudoexfoliation in Canada. Can J Ophthalmol 1999; 34: 257-265.

33 Yuksel N, Anik Y, Kilic A, Karabas V, Demirci A, Caglar Y. Cerebrovascular blood flow velocities in pseudoexfoliation. Graefes Arch Clin Exp Ophthalmol 2006; 244: 316-321.

34 Sainz Gomez C, Moreno-Montanes J, Escudero Berasategui JM, Sadaba Echarri LM, Fernandez Hortelano A, Garcia Layana A. Prevalence and risk factors of pseudoexfoliation syndrome in institutionalized geriatric patients in Navarra. Arch Soc Esp Ophthalmol 2003; 78: 383-388.

35 Visontai Z, Merisch B, Kollai M, Hollo G. Increase of carotid artery stiffness and decrease of baroreflex sensitivity in exfoliation syndrome and glaucoma. Br J Ophthalmol 2006; 90: 563-567.

36 Vessani RM, Ritch R, Liebmann JM, Jofe M. Plasma homocysteine is elevated in patients with exfoliation syndrome. Am J Ophthalmol 2003; 136: 41-46.

37 Allingham RR, Loftsdottir M, Gottfredsdottir MS, Thorgeirsson E, Jonasson F, Sverisson $\mathrm{T}$ et al. Pseudoexfoliation syndrome in Icelandic families. Br J Ophthalmol 2001; 85: 702-707.

38 Hietanen J, Soisalon-Soininen S, Kivela T, Tarkkanen A. Evaluation of the clinical association between exfoliation syndrome and abdominal aortic aneurysm. Acta Ophthalmol Scand 2002; 80: 617-619.

39 Ringvold A, Blika S, Sandvik L. Pseudo-exfoliation and mortality. Acta Ophthalmol Scand 1997; 75: 255-256.

40 Shrum KR, Hattenhauer MG, Hodge D. Cardiovascular and cerebrovascular mortality associated with ocular pseudoexfoliation. Am J Ophthalmol 2000; 129: 83-86.

41 Netland PA, Ye H, Streeten BW, Hernandez MR. Elastosis of the lamina cribrosa in pseudoexfoliation syndrome with glaucoma. Ophthalmology 1995; 102: 878-886.

42 Ringvold A, Vegge T. Electron microscopy of the trabecular meshwork in eyes with exfoliation syndrome. (Pseudoexfoliation of the lens capsule). Virchows Arch (Pathol Anat) 1971; 353: 110-127.

43 Streeten BW, Li ZY, Wallace RN, Eagle RC, Keshgegian AA. Pseudoexfoliative fibrillopathy in visceral organs of a patient with pseudoexfoliation syndrome. Arch Ophthalmol 1992; 110: 1757-1762. 